\title{
ULTRAESTRUTURA DO ESPERMATOZOIDE DE METANEPHROPS RUBELLUS (NEPHROPIDAE): ESPERMIOTAXONOMIA PODE SER DECISIVA PARA ELUCIDAR QUESTÕES FILOGENETICAS?
}

\author{
Santana, A.O. ${ }^{1}$; Mantelatto, F.L. ${ }^{2} \&$ Zara, F.J. ${ }^{1}$ \\ ${ }^{1}$ Universidade Estadual Paulista (UNESP), Faculdade de Ciências Agrarias e Veterinárias (FCAV), \\ Campus de Jaboticabal, Laboratório de Morfologia de Invertebrados (IML), Brasil. \\ ${ }^{24}$ Universidade de São Paulo (USP), Faculdade de Filosofia, Ciências e Letras de Ribeirão Preto (FFCLRP), \\ Campus de Ribeirão Preto, Laboratório de Bioecologia e Sistemática de Crustáceos (LBSC), Brasil \\ *Autor correspondente: santana.o.abner@gmail.com
}

A ultraestutura dos espermatozoides é conhecida para a maioria dos gêneros de Nephropidae Dana,1852, com exceção de Metanephrops Jenkins, 1972, o que dificulta estudos taxonômicos utilizando esta ferramenta. No Brasil, Metanephrops rubellus (Moreira, 1903) é um importante recurso pesqueiro. Neste trabalho descreve-se a ultraestrutura de espermatozoide de $M$. rubellus, comparando com descrições previas de outros gêneros da família. Espécimes foram coletados com NPq "Soloncy Moura" (CEPSUL-ICMBio) em São Sebastião (SP), Brasil. Amostras do sistema reprodutor foram fixadas e preparadas para rotina de microscopia eletrônica de transmissão. O espermatozoide é formado pelo acrossomo, citoplasma subacrosomal excêntrico e o núcleo no justaposto ao acrossomo. O acrossomo é um cilindro volumoso curto com complexo apical marcado por três áreas eletrondensas e nota-se um espessamento do material acrossomal interno, enquanto o material acrossomal externo alcança somente as margens do complexo. O material subacrosomal (câmara perforatorial) tem contato estreito com o complexo apical, e amplo na base com acentuada curvatura na altura do início da camada acrossomal interna. O material acrossomal interno e externo são amplos na base do acrossomo tornando-se estreitos junto ao complexo apical. O material acrossomal externo é granular e o interno dividido pelo material subacrossomal, com duas áreas apresentando eletrondensidade diferentes: 1 ) junto ao material subacrosomal menos eletrondenso e 2) área irregular em contato com o material acrossomal externo. O citoplasma excêntrico é volumoso com muitas mitocôndrias e restos de membrana, sendo o restante do espermatozoide preenchido pelo núcleo em forma de "C" com cromatina fibrosa. Análises morfológicas e moleculares produziram resultados conflitantes em relação ao gênero Nephrops Wood-Mason, 1872 onde a morfologia mostra Nephrops e Metanephrops como grupo-irmão, enquanto que a molecular coloca Homarus Weber, 1795 mais proximamente relacionada a Nephrops que Metanephrops. O espermatozoide Homarus e Nephrops possuem acrossoma muito alongado, material subacrossomal curto, nunca alcançando o complexo apical e fazendo com que o material acrossomal interno seja uma coluna única. Assim, a ultraestrutura do espermatozoide de Metanephrops suporta a filogenia molecular, indicando que a espermiotaxonomia é uma ferramenta importante ou decisiva a ser considerada para análises de parentesco.

Palavras-chave: espermiotaxonomia, lagostim, microscopia eletrônica de transmissão.

Financiamento: FAPESP (Biota) \#2010/50188-8, CAPES CIMAR II \#1989/2014 proc. $230380043092014-51$ e \# 2005/2014 proc. 23038.004308/2014-14. 